\title{
Participação da agricultura familiar na alimentação escolar no município de Passo Fundo-RS ${ }^{1}$
}

\author{
Participation of family agriculture in school feeding in the municipality of \\ Passo Fundo-RS
}

\author{
Indaia Dias Lopes \\ Universidade de Passo Fundo - Passo Fundo - Rio Grande do Sul - Brasil \\ ORCID https://orcid.org/0000-0003-2966-8461
}

\begin{abstract}
Resumo: O objetivo deste artigo é analisar a participação da agricultura familiar nas compras da alimentação escolar na rede escolar municipal de Passo Fundo, localizado no norte do estado do Rio Grande do Sul. Trata-se de uma pesquisa descritiva, com abordagem qualitativa dos dados coletados por meio de entrevistas, revisão bibliográfica e documental. A gestão da alimentação escolar centralizada na Prefeitura Municipal vem permitindo o estabelecimento de relações de confiança entre os diferentes atores sociais envolvidos: cooperativas fornecedoras, agricultores familiares e outros órgãos, como a Emater, o Conselho de Alimentação Escolar, o Conselho Municipal de Segurança Alimentar e a Coordenadoria de Nutrição Escolar. O processo de comercialização com fornecedores de produtos da agricultura familiar para a rede escolar municipal de Passo Fundo vem sendo aprimorado, com esforços dos diferentes atores sociais envolvidos, em busca de melhores resultados.
\end{abstract}

Palavras-chave: Alimentação escolar. Agricultura familiar. Mercados institucionais.

Abstract: The objective of this article is to analyze the participation of family farms in school feeding purchases in the municipal school network of Passo Fundo, located in the northern part of the state of Rio Grande do Sul. This is a descriptive research, with a qualitative approach to the data collected by interviews, bibliographical and documentary review. The management of school feeding centralized in the City Hall has allowed the establishment of relations of trust between the different social actors involved: cooperative suppliers, family farmers and other bodies, such as Emater, School Feeding Council, Municipal Council for Food Safety and the School Nutrition Coordinator. The marketing process with suppliers of family farming products to the

\footnotetext{
${ }^{1} O$ presente trabalho foi realizado com apoio da Coordenação de Aperfeiçoamento de Pessoal de Nível Superior - Brasil (CAPES). Registro meus agradecimentos ao professor Dr. David Basso pelas contribuições para a primeira versão deste estudo, isentando-o da responsabilidade por esta versão final.
} 
Participação da agricultura familiar na alimentação escolar no município de Passo Fundo-RS ${ }^{1}$

Passo Fundo municipal school network has been improved, with the efforts of the different social actors involved, in search of better results.

Keywords: School feeding. Family farming. Institutional markets.

\section{Introdução}

O Programa Nacional de Alimentação Escolar (PNAE) é considerado em nível mundial como um caso bem sucedido de programa de alimentação escolar (PAE) sustentável. Em função disso, o governo brasileiro possui acordos internacionais com a Organização das Nações Unidas para a Alimentação e a Agricultura (FAO) e com o Programa Mundial de Alimentos (PMA), os quais têm como objetivo apoiar o desenvolvimento de PAEs sustentáveis em países da América Latina, Caribe, África e Ásia, sob os princípios da segurança alimentar e nutricional e do direito humano à alimentação adequada (FNDE, 2016a).

A partir da Lei no 11.947/2009, foi regulamentado que as compras dos gêneros alimentícios para o PNAE poderiam ser realizadas por meio de um processo simplificado, denominado Chamada Pública² (FNDE, 2016b), permitindo que o processo licitatório fosse dispensado. A Chamada Pública pode ser realizada se: os preços forem compatíveis com os preços praticados no mercado local; forem respeitados os princípios presentes no artigo 37 da Constituição Federal de 1988 (legalidade, impessoalidade, moralidade, publicidade e eficiência); forem atendidas as exigências de controle de qualidade dos alimentos, as quais são estipuladas pelas normas que regem os editais de Chamada Pública.

A referida legislação favoreceu a conexão entre agricultura familiar e a alimentação escolar e também propiciou a construção de novos mercados pautados nos conceitos de Segurança Alimentar e Nutricional (SAN). O Brasil foi o primeiro país da América Latina que estabeleceu uma legislação regulamentando uma porcentagem dos produtos para a alimentação escolar com origem em produtos da agricultura familiar (FAO; OPAS, 2017).

Balem (2015) destaca que os municípios realizam a operacionalização dos recursos do PNAE de diferentes formas, de acordo com sua estrutura e especificidades locais. A viabilidade das políticas de aquisições de alimentos da agricultura familiar para a alimentação escolar, no entanto, necessita de uma estratégia e de envolvimento entre os atores locais. Tais estratégias devem ser construídas levando em consideração a realidade do município e orientadas pelo relacionamento entre os diferentes atores que fazem a operacionalização do programa, não pela lógica do mercado que tem como base a demanda e oferta de produtos. A legislação federal do PNAE terá ou não efetividade a

\footnotetext{
2 Nas compras da agricultura familiar para o PNAE é permitida a dispensa do processo licitatório tradicional (Lei no 8666/1993) e as compras podem ser realizadas por meio do instrumento de compra denominado Chamada Pública, desde que atendidos os preceitos constitucionais de legalidade, impessoalidade, moralidade, publicidade e eficiência e os preços estejam em conformidade com os preços médios praticados no mercado local (AMARAL, 2016).
} 
partir do nível local, dependendo da conscientização e liderança dos gestores, profissionais técnicos e da participação da sociedade civil (TRICHES; BACCARIN, 2016).

Neste contexto, o objetivo deste trabalho é analisar a participação da agricultura familiar nas compras da alimentação escolar nas escolas municipais de Passo Fundo, localizado no norte do estado do Rio Grande do Sul, identificando as oportunidades e os desafios enfrentados pelos atores sociais que fazem a operacionalização do programa.

Justifica-se a escolha de Passo Fundo enquanto lócus de pesquisa por esta ser a maior cidade do norte do Rio Grande do Sul, considerada uma cidade média, possuindo uma população estimada de 201.767 habitantes (IBGE, 2019). Ademais, Passo Fundo possui 70 escolas municipais, com mais de 17.000 alunos matriculados (FNDE, 2017), se constituindo em um importante mercado para a agricultura familiar, o que torna, assim, relevante verificar como ocorre a participação desta categoria social enquanto fornecedor para as escolas municipais.

O artigo está organizado em cinco seções, iniciando por esta introdução. A segunda seção apresenta a perspectiva histórica, bem como o atual contexto da agricultura familiar no Brasil. Na terceira seção aborda-se a processualidade metodológica e, na quarta seção são apresentados os resultados da operacionalização do PNAE nas escolas municipais de Passo Fundo, finalizando com as considerações finais.

\section{A agricultura familiar brasileira e a alimentação escolar}

Para Wanderley (1999), a agricultura familiar pode ser entendida como aquela em que a família detém a propriedade dos meios de produção e, além disso, assume o trabalho no estabelecimento produtivo. Os estudos sobre a agricultura familiar evidenciam que esta é uma forma social reconhecida e legitimada em uma parcela significativa dos países desenvolvidos que possuem uma estrutura agrária composta por um número expressivo de explorações, cujo trabalho dos membros da família não só é majoritário, mas também possui poder de decisão (SCHNEIDER, 2003).

A produção familiar caracteriza-se pelo controle da família sobre os meios de produção, sendo que ao mesmo tempo, é a principal responsável pela efetivação do trabalho. Neste sentido, Lamarche (1993, p. 15) destaca que a exploração familiar corresponde a:

[...] a uma unidade de produção agrícola onde propriedade e trabalho estão intimamente ligados à família. A interdependência desses três fatores no funcionamento da exploração engendra necessariamente noções mais abstratas e complexas, tais como a transmissão do patrimônio e a reprodução da exploração.

Segundo Wanderley (1996), historicamente o campesinato ${ }^{3}$ brasileiro é marcado pela luta dos camponeses para ter acesso ao mercado e por diversas derrotas nos

\footnotetext{
${ }^{3}$ Compreende-se aqui a agricultura camponesa tradicional a partir dos conceitos utilizados por Wanderley (1996), a qual considera a mesma enquanto uma das formas sociais da agricultura familiar, tendo em vista que ela é pautada nas relações entre propriedade, trabalho e família. Deve-se considerar, segundo a
} 
embates vivenciados. Para a referida autora, um dos aspectos mais relevantes da luta dos camponeses brasileiros situa-se no esforço realizado para constituir um "lugar de vida e de trabalho, capaz de guardar a memória da família e de reproduzi-la para as gerações posteriores" (p. 12).

A agricultura familiar brasileira contém muitas características camponesas. Por sua vez, a constituição do campesinato no país "tem como base o acesso a terra e a reprodução de formas particulares de produção e de sociabilidade" (WANDERLEY, 1999, p. 52).

A Constituição Federal de 1988 representou um marco legal para a agricultura familiar brasileira enquanto categoria social, oportunizando novos espaços para participação social e direitos reconhecidos. A criação do Programa Nacional de Fortalecimento da Agricultura Familiar (PRONAF), em 1995, resultou na necessidade de outras políticas diferenciadas para o desenvolvimento rural, assim como a criação do Ministério do Desenvolvimento Agrário (MDA) em 1999 e, no âmbito deste, a criação da Secretaria da Agricultura Familiar (SAF) em 2001 (GRISA; SCHNEIDER, 2015).

O aspecto territorial está presente na temática da agricultura familiar, principalmente sob três aspectos (MALUF, 2004). Em primeiro lugar, as estratégias utilizadas para agregação de valor dos produtos agrícolas pelos próprios agricultores familiares, pautadas na construção de uma identidade territorial, de onde advém parte significativa do valor que se deseja atribuir aos bens. O segundo aspecto está relacionado ao território, pois permite introduzir a possibilidade de aproximar as relações entre a produção e o consumo dos alimentos, em que os fatores positivos se concentram também na qualidade e confiabilidade dos produtos e na sua maior identificação por meio de hábitos de consumo diferenciados. O terceiro ponto se refere aos projetos produtivos dos agricultores inseridos em uma dinâmica regional, a abordagem espacial-territorial aumenta as possibilidades de eventuais benefícios de aglomeração.

A agricultura familiar diversificada oferece oportunidades para que se estabeleçam relações produtivas e comerciais, no âmbito regional, direcionados a produção, distribuição e consumo de alimentos diferenciados. Neste sentido, Maluf (2004) ressalta que é importante a elaboração de ações públicas voltadas à promoção da produção e do consumo de alimentos regionais de qualidade, sob a forma de programas do governo e projetos que envolvam organizações não governamentais e entidades representativas dos agricultores e dos consumidores.

Os agricultores familiares enfrentam diversos desafios para acessar os mercados, tais como: dificuldades de transporte/logística, dificuldades para conhecer os preços e para identificar a preferência dos consumidores. Os mercados são controlados por atores que possuem o monopólio de transporte, de formação de preços, de acesso aos consumidores e, neste contexto, os agricultores familiares são desfavorecidos (SCHNEIDER, 2017).

autora, que o campesinato tradicional possui algumas particularidades que o especificam no conjunto da agricultura familiar. 
Participação da agricultura familiar na alimentação escolar no município de Passo Fundo-RS ${ }^{1}$

De acordo com Schneider e Cassol (2017), tendo como base o Censo Agropecuário do IBGE de 2006, o Brasil possuía neste período um total de 5.175.489 estabelecimentos agropecuários, destes 4.367 .902 enquadravam-se na classificação de agricultores familiares. Para os autores, a agricultura familiar brasileira representa $84 \%$ dos estabelecimentos agropecuários do país ocupando uma área em torno de 80,3 milhões de hectares, correspondendo a $24,3 \%$ da área total dos estabelecimentos rurais. Os referidos autores destacam que a agricultura familiar brasileira contribui para a produção agropecuária com $38 \%$ do valor da produção e $34 \%$ do total das receitas deste setor têm origem no mesmo. No entanto, apesar dos estabelecimentos não familiares representarem um total de $16 \%$ do total de unidades, eles ocupam $76 \%$ da área de terra e contribuem com a maior parte da produção e da receita do agro brasileiro: $62 \%$ e $66 \%$, respectivamente.

O Estado possui importante papel no abastecimento alimentar e nas políticas de segurança alimentar e pode atuar em setores em que os mercados enfrentam dificuldades (SCHNEIDER, 2017). Assim sendo, o governo brasileiro, ao implementar a Lei no 11.947/2009, utilizou das compras públicas para beneficiar a alocação dos agricultores familiares locais aos mercados institucionais de alimentação escolar (TRICHES, 2015). Ainda existem entraves operacionais, estruturais, políticos e econômicos que devem ser enfrentados na construção e gerenciamento desse mercado, mas cabe ressaltar que a ação e relação entre os atores sociais envolvidos no processo de aquisição pública é um dos aspectos fundamentais para que a legislação tenha ou não efetividade (AUTOR, 2018).

\section{Procedimentos metodológicos}

Este estudo insere-se na perspectiva da História do Tempo Presente, tendo em vista que trata-se de um fenômeno contemporâneo, onde o período de análise inicia-se no ano de 2009, quando foi implementada a Lei no 11.947 incluindo o agricultor familiar como fornecedor do PNAE, e estende-se até 2017, ano em que foi realizada a pesquisa de campo junto aos atores sociais envolvidos na operacionalização do Programa em Passo Fundo. Conforme Delgado e Ferreira (2013, p. 23-24), a História do Tempo Presente "tem no recorte temporal da contemporaneidade a sua marca".

O presente estudo configura-se como uma pesquisa descritiva, com abordagem qualitativa dos dados (GIL, 2016). Quanto ao delineamento, o estudo envolveu pesquisa de campo, fontes orais, documental e bibliográfica.

Foram realizadas entrevistas com 15 atores sociais envolvidos direta e indiretamente na operacionalização do PNAE no âmbito municipal, os quais são identificados no texto por uma letra com o objetivo de preservar a identidade dos depoentes: a) nutricionistas da Coordenadoria de Nutrição Escolar e Secretário Municipal de Educação (PM); b) extensionistas da Emater (E); c) diretoras, funcionárias e merendeiras de escola (EM).

Para Alberti (2008, p. 165), uma das principais contribuições da utilização de fontes orais consiste em "permitir o estudo da forma como as pessoas ou grupos 
efetuaram ou elaboraram experiências". Por meio da memória dos informantes o historiador recupera e recria o objeto de estudo, permitindo orientar as reflexões históricas, criando desdobramentos teóricos e metodológicos significativos (FERREIRA, 2012). As entrevistas foram gravadas em áudio, sendo posteriormente transcritas e salvas individualmente em um arquivo eletrônico Word ${ }^{\circledR}$.

\section{O município de Passo Fundo (RS) e a rede escolar municipal}

O município de Passo Fundo foi fundado em 07/08/1857 a partir de desmembramento do município de Cruz Alta (IBGE, s/d) e localiza-se no norte do Estado do Rio Grande do Sul (RS). É considerada uma cidade de porte médio, com uma população estimada para 2017 em 198.799 habitantes e uma área de 783,421 km² (IBGE, 2017), com $90 \%$ de sua área rural, $60 \%$ da qual destinada à produção de milho, trigo e soja e os outros $30 \%$ utilizados para atividades como a avicultura, bovinocultura de leite e a horticultura (ALBRECHT et al., 2015). Este município integra o Conselho Regional de Desenvolvimento (COREDE) ${ }^{4}$ Produção que congrega 21 municípios, totalizando 358.923 habitantes (FEE, 2015), sendo Passo Fundo o principal centro urbano deste Corede.

Na Figura 1 apresenta-se o mapa do Rio Grande do Sul, com a localização de Passo Fundo destacada ao centro do mapa.

Figura 1 - Localização geográfica de Passo Fundo, RS

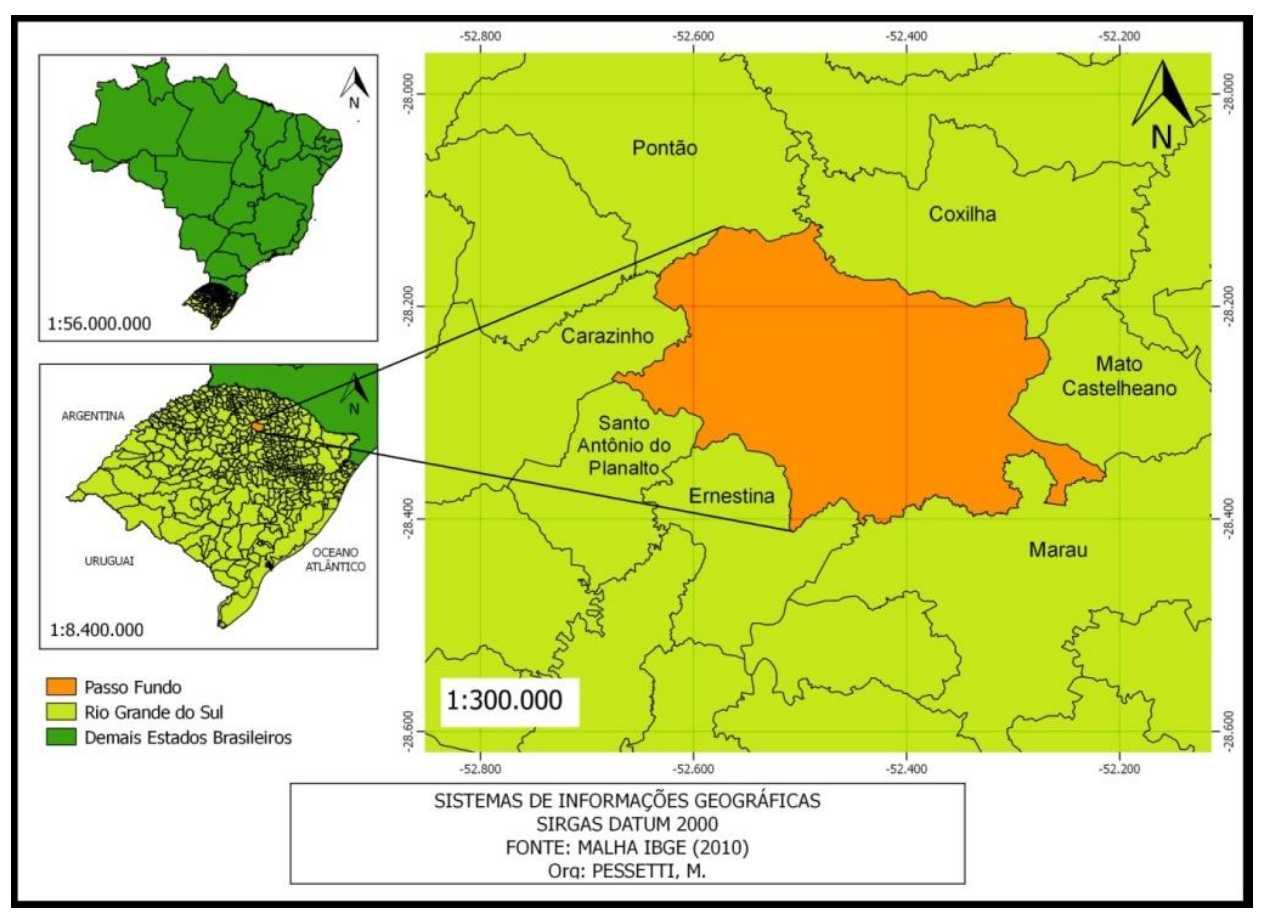

Fonte: Elaborado a partir de IBGE (2010)

\footnotetext{
${ }^{4}$ Os COREDEs foram institucionalizados com a Lei no 10.283 de 17/10/1994 e se constituem em um fórum de discussão para a promoção de políticas que promovam o desenvolvimento regional. Atualmente o RS possui 28 COREDEs e a cidade de Passo Fundo integra o COREDE Produção (ATLAS SOCIOECONOMICO RS, 2017).
} 
O Produto Interno Bruto (PIB) per capita de Passo Fundo é de R\$42.459,59 (IBGE, 2019). A economia do município é relativamente diversificada e apresenta um perfil mais voltado às atividades industriais e de serviços. O Índice de Desenvolvimento Humano Municipal (IDHM) calculado para o ano de 2010 para Passo Fundo foi de 0,776, situado na faixa de IDHM alto. Em relação à situação domiciliar da população, os dados disponíveis são de 2010 e indicam que, naquele ano 180.120 pessoas residiam em zona urbana e 4.706 na zona rural, perfazendo o total de 184.826 habitantes, de acordo com os dados do IBGE (2010b). Isso significa que apenas $2,5 \%$ da população do município residiam no meio rural em 2010, indicando o predomínio de um perfil de estabelecimentos agropecuários de média e grande escala.

De acordo com Fritz Filho (2009), o dinamismo do espaço econômico rural do município teve, historicamente, como principais atores os granjeiros, as cooperativas, as agroindústrias e os comerciantes urbanos. Esta dinâmica, segundo o autor, ampliouse a partir de 1965, com o incremento da lavoura empresarial da soja, atingindo o apogeu em 1970, momento em que esta cultura assumiu o protagonismo no processo de modernização da agricultura desta região.

A partir de 1978/1979 observa-se a busca por diversificar as culturas para que a agricultura de Passo Fundo não ficasse na dependência de apenas duas safras, com as culturas de trigo no inverno e de soja no verão (BRUM, 1983). A partir dos anos 1990, as unidades de produção agrícola em Passo Fundo caracterizam-se por conviver, em um mesmo território, com diferentes configurações produtivas, conforme destaca Fritz Filho (2009, p. 27):

unidades de produção agrícola destinadas unicamente à produção de culturas de verão e inverno, unidades com atividades de integração indústriaprodutor familiar e produção de soja, propriedades com atividades de cultivo de soja e criação, unidades com produção de hortifrutigranjeiros, entre outras.

Ainda que Passo Fundo seja um município com o espaço agrícola caracterizado pela agricultura moderna, a presença da agricultura familiar é significativa (TEDESCO, 2006), conforme consta na Tabela 1 elaborada a partir dos dados preliminares do Censo Agropecuário do IBGE de 2017.

Uma parcela significativa dos estabelecimentos com menos de 100 ha deve ser de produtores familiares, mas os que se envolvem com mercados institucionais seguramente estão no estrato de menos de 20 ha. Mais de $50 \%$ dos agricultores de Passo Fundo estão neste estrato de área, mas eles utilizam 7\% da área total destinada para a agricultura deste município e, muito provavelmente, em regiões onde o relevo e o solo não sejam os melhores para as práticas agropecuárias. A concentração da terra é marcante na agricultura de Passo Fundo. De um lado cerca de $73 \%$ dos estabelecimentos têm menos de 50 hectares e possuem, juntos, em torno de $17 \%$ da área total, enquanto do outro $15,4 \%$ dos estabelecimentos têm mais de 100 hectares e detêm próximo de $70 \%$ da área total. 
Participação da agricultura familiar na alimentação escolar no município de Passo Fundo-RS ${ }^{1}$

Tabela 1- Número de estabelecimentos agropecuários e Área dos estabelecimentos por grupos de área total do Município de Passo Fundo - RS, 2017

\begin{tabular}{c|c|c|c|c}
\hline $\begin{array}{c}\text { Grupos de área total } \\
\text { (hectares-ha) }\end{array}$ & $\begin{array}{c}\text { Número de } \\
\text { estabelecimentos }\end{array}$ & $\%$ & $\begin{array}{c}\text { Área dos } \\
\text { estabelecimentos }\end{array}$ & $\%$ \\
\hline De 0 a menos de 20 ha & 487 & 54,1 & 3.605 & 7 \\
\hline $\begin{array}{c}\text { De } 20 \text { a menos de } 50 \\
\text { ha }\end{array}$ & 171 & 19 & 5.414 & 10,5 \\
\hline $\begin{array}{c}\text { De } 50 \text { a menos de } 100 \\
\text { ha }\end{array}$ & 103 & 11,5 & 6.913 & 13,4 \\
\hline $\begin{array}{c}\text { De } 100 \text { a menos de } \\
500 \text { ha }\end{array}$ & 117 & 13 & 25.155 & 48,9 \\
\hline De 500 ha e mais & 22 & 2,4 & 10.383 & 20,2 \\
\hline TOTAL & 900 & 100,0 & 51.470 & 100 \\
\hline
\end{tabular}

Fonte: IBGE (2018)

Conforme diagnóstico da produção agrícola municipal realizado pela Emater Municipal de Passo Fundo em 2015, a área total do município corresponde a 75.830 ha, destes 7.800 ha (10,2\% da área) correspondem a área urbana do município e 68.030 ha $(89,80 \%$ da área) correspondem a área rural. Destes 68.030 ha de área rural predominam 38.500 ha com plantio de soja e 2.000 ha com o plantio de milho no período de verão. Os outros usos do solo dividem-se em: matos, potreiros, pastagens, banhados, estradas, reservatórios e sedes das propriedades.

O setor educacional público municipal de Passo Fundo é composto por 70 escolas municipais, que estão subordinadas à Secretaria Municipal de Educação de Passo Fundo.

A gestão do PNAE nas escolas municipais de Passo Fundo é centralizada na Prefeitura Municipal, sendo esta a Entidade Executora ${ }^{5}$ (EEx), por meio da Secretaria Municipal de Educação, representada pela Coordenadoria de Nutrição Escolar (CNE). Esta modalidade de gestão do PNAE é conhecida como centralizada ou municipalizada, onde as compras são centralizadas no município, neste caso na CNE, que faz as compras para todas as escolas da rede municipal. Além das escolas da rede municipal, existem oito escolas filantrópicas no município de Passo Fundo, que oferecem alimentação escolar aos seus alunos com recursos advindos do FNDE. Estes recursos são recebidos pela Secretaria Municipal de Educação que faz a gestão dos mesmos juntamente com os recursos destinados as escolas municipais. A distribuição do número de alunos na rede escolar municipal de Passo Fundo, incluindo as escolas filantrópicas que recebem recursos para o PNAE, estão organizadas no Quadro 1.

\footnotetext{
${ }^{5}$ As Entidades Executoras (EExs) incluem os estados e o Distrito Federal, os municípios e as escolas federais de educação básica. As EExs, mediante o recebimento dos recursos executam o PNAE em suas respectivas redes escolares, utilizando-se das formas operacionais previstas na legislação em vigor. Cada EEx responsabiliza-se pela execução do PNAE em suas respectivas redes de ensino.
} 
Participação da agricultura familiar na alimentação escolar no município de Passo Fundo-RS ${ }^{1}$

Quadro 1 - Rede escolar pública municipal de Passo Fundo, 2017

\begin{tabular}{|l|c|c|}
\cline { 2 - 3 } \multicolumn{1}{c|}{} & $\begin{array}{l}\text { No de } \\
\text { Escolas }\end{array}$ & № de Alunos \\
\hline Educação Infantil & 35 & 5.158 \\
\hline Ensino Fundamental & 35 & 10.274 \\
\hline Filantrópicas & 8 & 2.085 \\
\hline Total & $\mathbf{7 8}$ & $\mathbf{1 7 . 5 1 7}$ \\
\hline
\end{tabular}

Fonte: Dados da pesquisa

A rede escolar municipal de Passo Fundo é constituída por 70 escolas, sendo 35 Escolas Municipais de Educação Infantil (EMEI) e 35 Escolas Municipais de Ensino Fundamental (EMEF), conforme observa-se no Quadro 1.

\section{O PNAE nas escolas municipais de Passo Fundo}

As compras de produtos para a alimentação escolar da rede municipal de Passo Fundo foram centralizadas na CNE até o ano de 2009, realizadas em sua totalidade por meio de Licitação (Lei no 8.666/1993), levando em consideração o menor preço.

As compras para a alimentação escolar são realizadas pela CNE em duas modalidades: a) Pregão eletrônico (Lei no 8666/1993) para itens de supermercados locais, e b) Chamada Pública para itens de agricultores familiares. Conforme Schneider (2016), os mecanismos de regulação dos mercados institucionais se dão por contratos públicos e regidos por legislação específica, no caso do PNAE a Lei no 11.947/2009, o que limita a sua agilidade, porém, possibilita um maior controle para o gestor público.

Os itens não perecíveis são entregues pelos vencedores das licitações ou das Chamadas Públicas diretamente no depósito da CNE, já os itens perecíveis, tais como hortifrutigranjeiros e panificados são entregues pelos fornecedores (agricultores, associações ou cooperativas familiares) diretamente nas escolas, com periodicidade semanal ou conforme a necessidade da escola. A CNE possui caminhão próprio para fazer a entrega dos produtos nas escolas, tendo este veículo uma parte com refrigeração, própria para o transporte de alimentos, como carnes, lácteos.

A CNE possui sede própria e separada das instalações da Prefeitura Municipal. Neste local ficam lotados os funcionários que desempenham atividades relacionadas à alimentação escolar: duas nutricionistas, sendo uma delas a Coordenadora de Nutrição Escolar e Nutricionista Responsável Técnica (RT) pelo PNAE, uma funcionária responsável por encaminhar os alimentos para as escolas, uma funcionária responsável por controlar os alimentos do estoque, um menor aprendiz, três motoristas (terceirizados) para realizar as entregas nas escolas e uma servente responsável pela limpeza do setor. A atuação do profissional nutricionista é fundamental para a execução do PNAE, sendo que este profissional tem a competência de realizar atividades de 
planejamento, coordenação, direção, supervisão e avaliação de todas as ações de alimentação e nutrição no âmbito da alimentação escolar (TCU, 2017).

Quanto à origem dos recursos financeiros, o FNDE faz o repasse dos valores em dez parcelas ao ano para a cobertura de 200 dias letivos (FNDE, 2015) e é realizada uma complementação $^{6}$ com recursos financeiros da Prefeitura Municipal. Esta complementação é realizada somente para as escolas municipais, as escolas filantrópicas recebem somente os alimentos adquiridos com recursos advindos do FNDE.

As escolas municipais apenas executam o PNAE, o que se resume a receber os alimentos dos fornecedores, fazer o preparo dos mesmos e oferecer as refeições aos alunos. $O$ processo de planejamento, negociação com fornecedores e elaboração dos processos de compra são de responsabilidade da CNE.

Quando a Lei no 11.947/2009 passou a vigorar não existia ainda fornecedores da agricultura familiar organizados no município de Passo Fundo para abastecer a alimentação escolar, dessa forma, a CNE precisou identificar se no município havia agricultores familiares individuais ou organizados em cooperativas que pudessem suprir este mercado.

Em primeiro lugar, a CNE entrou em contato com a Feira dos Produtores ${ }^{7}$ buscando informações sobre a oferta dos produtos e para verificar se esses agricultores teriam condições de participar do PNAE. Assim, alguns agricultores familiares participantes da Feira do Produtor se organizaram e criaram a Associação de Agricultores Familiares de Passo Fundo e Região (AGROPASSO) em 2010, a qual atendeu a alimentação escolar da rede municipal até 2012. Após este período, alguns agricultores familiares saíram e associaram-se na Cooperativa dos Produtores de Leite de Passo Fundo (AGROLEITE). Estas instituições foram desarticuladas, segundo relatado nas entrevistas, devido principalmente a problemas de gestão, relacionados ao cumprimento de compromissos assumidos na habilitação à Chamada Pública, tais como a quantidade e qualidade dos produtos, bem como a regularidade das entregas.

Com a inserção da atual nutricionista da CNE, no final do ano de 2012, identificou-se diversos problemas com os fornecedores da agricultura familiar, tais como: entrega de alimentos diferentes aos solicitados, embalagens inadequadas, dentre outros. Para participar da Chamada Pública as cooperativas de agricultores familiares apresentavam alimentos de boa qualidade nas amostras, mas nas escolas eram entregues produtos com outro padrão de qualidade.

Para que fosse possível construir um diálogo com fornecedores da agricultura familiar visando qualificar a alimentação escolar e cumprir o disposto no artigo 14 da Lei no 11.947/2009 foi necessário criar relações e parcerias com duas importantes

\footnotetext{
${ }^{6}$ A complementação financeira realizada pela Prefeitura Municipal de Passo Fundo varia de um ano para o outro, tendo chegado, em 2016, a quase duas vezes o valor repassado pelo FNDE.

${ }^{7}$ A Feira do Produtor iniciou no ano de 1975, em Passo Fundo, com a participação de 12 famílias de feirantes que vendiam os produtos oriundos da lavoura. Desde então, essa feira é realizada semanalmente em frente ao Parque da Gare e atualmente conta com a participação de mais de 70 grupos de agricultores (TEDESCO, 2006).
} 
instituições: a Unidade de Cooperativismo (UCP) da Emater de Erechim e o Escritório municipal da Emater de Passo Fundo. A UCP da Emater atua com as Cooperativas de agricultores familiares auxiliando na documentação, legislação, alvará sanitário, na organização de produção, dentre outras atividades. Já o Escritório municipal da Emater de Passo Fundo, atua diretamente com os agricultores familiares, auxiliando com a realização de oficinas, tais como: para formação de preços para os produtos, preparação de bolachas, instruções sobre a elaboração de embalagens, dentre outras.

Com a participação da UCP da Emater de Erechim, a partir de 2013, foi desenvolvido um trabalho de sensibilização e motivação entre os atores sociais envolvidos com a alimentação escolar na rede municipal ampliar a aquisição de produtos de agricultores familiares. Estavam envolvidos: o secretário de educação, as nutricionistas do programa, a Emater, o Conselho de Alimentação Escolar (CAE), o Conselho Municipal de Segurança Alimentar (Comsea) e cooperativas de agricultores familiares, dentre outros.

Foram realizadas reuniões de articulação entre os representantes dos referidos órgãos com vistas a buscar mútuos entendimentos acerca da legislação, a fim de construir um diálogo entre esses diferentes atores envolvidos direta ou indiretamente com a alimentação escolar, identificando as dificuldades existentes tanto do lado da oferta quanto da demanda e criando estratégias para superar os problemas e aprimorar o processo de comercialização. Este processo foi assim destacado por um dos extensionistas da Emater:

Foram várias ações, seminários, oficinas de cooperativismo e PNAE, a gente sempre tratava do cooperativismo e do PNAE como foco nos aspectos legais e operacionais. Aspectos legais é o que? Quais são os critérios de seleção, tem que ter a $\mathrm{DAP}^{8}$ emitida nos últimos 30 dias e agora emitida nos últimos 60 dias, habilitação sanitária dos alimentos, uma amostra e degustação dos alimentos que era feita. As entidades executoras tinham uma conversa direta com as cooperativas e com os agricultores: opa, esta tua laranja tá muito murcha, o bolo não sei o que; o.doce, ou o pastel assado, não tá muito bom. Estas adequações e encaminhamentos eram dados diretamente pela entidade executora e as cooperativas (E1).

Este tipo de ação visando a união de forças em prol de um objetivo ganha guarida nas palavras de Abramovay (2004, p. 47-48):

O desenvolvimento dos mercados supõe formas localizadas, concretas de cooperação para as quais as ciências sociais contemporâneas voltam de maneira crescente seus estudos. Sob essa ótica, são muito mais que a soma cega e inconsciente de interesses privados, cujos protagonistas reúnem produzindo uma ordem que ninguém previu e sobre a qual ninguém tem

\footnotetext{
${ }^{8}$ A Declaração de Aptidão ao Pronaf (DAP) é um documento de identificação da agricultura familiar e pode ser obtida pelo agricultor ou pela agricultora, pessoa física e também pelo empreendimento familiar rural, tais como associações, cooperativas e agroindústrias, nestes casos pessoa jurídicas. Este documento é obtido gratuitamente em entidade e órgãos públicos autorizados pela SEAD para emitir a DAP (SEAD, 2018).
} 
controle. Eles envolvem algumas formas voluntárias de cooperação sem as quais nunca poderiam funcionar.

Ainda, conforme o relato do extensionista da Emater, quando iniciado este trabalho de aproximação entre a Emater e a CNE, no ano de 2013, havia quatro organizações da agricultura familiar, fornecendo alimentos para a rede municipal. Ao final de 2015, o entrevistado destaca que já eram 11 organizações, resultando na inclusão de novas cooperativas da agricultura familiar, oportunizando o acesso ao mercado por atores sociais até então excluídos e também, possibilitando ofertar uma maior diversidade de produtos.

Na Tabela 2 pode-se observar a evolução da operacionalização do PNAE relativa aos recursos repassados pelo FNDE para a rede municipal de ensino de Passo Fundo ${ }^{9}$.

Na linha que corresponde ao número de escolas, já estão incluídas as escolas filantrópicas, com exceção dos anos 2011 e 2012, pois nesses anos não foi possível o acesso aos dados dessas instituições. Os recursos repassados pelo FNDE para a alimentação escolar são definidos a partir do número de alunos matriculados de acordo com o censo do ano anterior ao repasse dos recursos, variando conforme a modalidade de ensino, o que explica que mesmo aumentando o número de alunos nos últimos anos, os recursos tiveram uma redução.

Na primeira coluna da Tabela 2, a linha que corresponde a $\mathrm{R} \$ 30 \%$, apresenta-se em valores monetários (R\$) os $30 \%$ dos recursos que o FNDE repassou ao município na série analisada, o que seria o mínimo a ser investido em compras da agricultura familiar. $E$, na linha abaixo, apresenta em termos absolutos, também em valores monetários ( $R \$$ ), quanto foi efetivamente investido em compras da agricultura familiar.

Nos anos de 2014, 2015 e 2017 foi possível elevar a participação das compras da agricultura familiar no total das compras realizadas para as escolas municipais com recursos do FNDE. Em parte, atribui-se esta elevação das compras da agricultura familiar ao esforço empreendido pela equipe da CNE em parceria com a Emater (UCP e Emater municipal), buscando aprimorar a comercialização com a qualificação dos fornecedores da agricultura familiar.

A modalidade de aquisição utilizada pela CNE para as compras de agricultores familiares até o ano de 2014 era feita por Chamada Pública, considerando o "menor preço global por item", e não pelo preço de aquisição ${ }^{10}$, conforme determina a resolução no 15 de 4 de abril de 2015. Dessa forma, os fornecedores que apresentavam as propostas com menor preço venciam o processo.

\footnotetext{
${ }_{9}^{9}$ Devido à falta de funcionários no departamento financeiro da Prefeitura Municipal de Passo Fundo, não foi possível ter acesso aos valores dos recursos destinados pela Prefeitura para toda a série analisada (2011 a 2017), por isso optou-se por apresentar somente a operacionalização dos recursos repassados pelo FNDE. ${ }^{10} \mathrm{O}$ preço de aquisição é o preço médio pesquisado por, no mínimo, três mercados locais, territoriais, estaduais ou nacionais, nessa ordem, com prioridade, quando houver, para a Feira do Produtor da Agricultura Familiar. Tais pesquisas devem contemplar produtos que possuam as mesmas condições de embalagens e logística de entrega, devendo ser publicados no edital de Chamada Pública (MDA, 2017).
} 
Participação da agricultura familiar na alimentação escolar no município de Passo Fundo-RS ${ }^{1}$

Tabela 2 - Evolução da operacionalização do PNAE nas escolas municipais de Passo Fundo, 2011-2017

\begin{tabular}{|c|c|c|c|c|c|c|c|}
\hline & 2011 & 2012 & 2013 & 2014 & 2015 & 2016 & 2017 \\
\hline $\begin{array}{l}\text { № de } \\
\text { Escolas }\end{array}$ & 62 & 62 & 71 & 76 & 76 & 76 & 78 \\
\hline $\begin{array}{l}\text { № de } \\
\text { Alunos }\end{array}$ & 13.552 & 14.090 & 16.055 & 14.105 & 14.105 & 15.350 & 15.500 \\
\hline $\begin{array}{l}\text { Recursos } \\
\text { do FNDE }\end{array}$ & $\begin{array}{c}1.295 .58 \\
0,00\end{array}$ & $\begin{array}{c}1.559 .79 \\
6,00\end{array}$ & $\begin{array}{c}1.785 .38 \\
4,00\end{array}$ & $\begin{array}{c}1.660 .56 \\
0,00\end{array}$ & $\begin{array}{c}1.784 .76 \\
8,00\end{array}$ & $\begin{array}{c}1.216 .98 \\
6,00\end{array}$ & $\begin{array}{c}1.727 .58 \\
4,00\end{array}$ \\
\hline $\mathrm{R} \$ 30 \%$ & $\begin{array}{c}388.674 \\
00\end{array}$ & $\begin{array}{c}467.938 \\
80\end{array}$ & $\begin{array}{c}535.615 \\
20\end{array}$ & $\begin{array}{c}448.351 \\
20\end{array}$ & $\begin{array}{c}527.760 \\
00\end{array}$ & $\begin{array}{c}365.986 \\
00\end{array}$ & $\begin{array}{c}518.275 \\
20\end{array}$ \\
\hline $\begin{array}{l}\mathrm{RS} \\
\text { absoluto }\end{array}$ & 0 & $\begin{array}{c}535.866 \\
04\end{array}$ & $\begin{array}{c}477.768 \\
75\end{array}$ & $\begin{array}{c}515.054 \\
92\end{array}$ & $\begin{array}{c}957.884 \\
98\end{array}$ & $\begin{array}{c}406.473 \\
32\end{array}$ & $\begin{array}{c}932.895 \\
36\end{array}$ \\
\hline$\%$ da AF & 0 & $34,35 \%$ & $26,76 \%$ & $34,46 \%$ & $53,67 \%$ & $33,4 \%$ & $54 \%$ \\
\hline $\begin{array}{l}\text { Modalid } \\
\text { ade de } \\
\text { aquisição }\end{array}$ & $\begin{array}{c}\text { Não } \\
\text { houve } \\
\text { Chamada } \\
\text { Pública } \\
\text { para } \\
\text { agricultu } \\
\text { ra } \\
\text { familiar }\end{array}$ & $\begin{array}{l}\text { Chamada } \\
\text { Pública } \\
\text { "Menor } \\
\text { Preço } \\
\text { Global } \\
\text { por } \\
\text { item" }\end{array}$ & $\begin{array}{l}\text { Chamada } \\
\text { Pública } \\
\text { "Menor } \\
\text { Preço } \\
\text { Global } \\
\text { por } \\
\text { item" }\end{array}$ & $\begin{array}{l}\text { Chamada } \\
\text { Pública } \\
\text { "Menor } \\
\text { Preço } \\
\text { Global } \\
\text { por } \\
\text { item" }\end{array}$ & $\begin{array}{c}\text { Concorrê } \\
\text { ncia } \\
\text { Pública }\end{array}$ & $\begin{array}{c}\text { Chamada } \\
\text { Pública }\end{array}$ & $\begin{array}{c}\text { Chamada } \\
\text { Pública }\end{array}$ \\
\hline
\end{tabular}

Fonte: Dados da pesquisa

No ano de 2015, as compras da agricultura familiar foram realizadas por Concorrência Pública ao invés do processo de Chamada Pública. Para a CNE, o objetivo da realização desta modalidade de aquisição era alertar os agricultores que, se não houvesse uma organização nas entregas, eles acabariam sendo excluídos do mercado institucional. A partir de 2016, a modalidade de aquisição da agricultura familiar foi a Chamada Pública, considerando o preço de aquisição. Essas alterações na modalidade de aquisição, como pode-se observar na Tabela 1, se devem, em parte, pelo trabalho de entendimento da legislação por parte da CNE, o qual foi desenvolvido conjuntamente entre a própria coordenadoria com auxílio da UCP da Emater de Erechim.

No ano de 2016 ocorreu uma redução significativa dos recursos destinados às compras da agricultura familiar para o PNAE, comparado ao ano anterior, com aumento no ano de 2017. A CNE explica que foram reduzidos os recursos financeiros destinados pela Prefeitura Municipal para a alimentação escolar, assim, foi necessário reduzir 
Participação da agricultura familiar na alimentação escolar no município de Passo Fundo-RS ${ }^{1}$

também as compras em produtos da agricultura familiar com os recursos do FNDE para poder atender a totalidade das escolas.

\section{Participação da agricultura familiar no PNAE em Passo Fundo}

A obrigatoriedade prevista em Lei de adquirir um percentual mínimo em produtos de agricultores familiares (30\% dos repasses do FNDE) traz consigo benefícios, mas também dificuldades para os atores sociais envolvidos. Por um lado, possibilita que sejam adquiridos gêneros alimentícios de agricultores locais e isto contribui para fomentar a economia local, se constituindo em um importante mercado para estes agricultores. Conforme o depoimento de um dos informantes:

O PNAE está avançando e pode chegar nos parâmetros dos programas de alimentação escolar os quais alguns países desenvolvidos estão apresentando. O Brasil está caminhando na direção de melhorias, em um processo de amadurecimento do programa e com a segurança de uma legislação específica para o mesmo (PM2).

No entanto, com a referida Lei, a CNE defrontou-se com um "despreparo" por parte dos agricultores familiares locais para participar do mercado gerado pela alimentação escolar. Dentre as principais dificuldades enfrentadas a partir de 2013 na operacionalização do PNAE em relação às compras da agricultura familiar no âmbito da rede escolar municipal, a CNE destacou: exigências sanitárias (alvarás), padronização na rotulagem dos produtos, falta de conhecimento do agricultor sobre comercialização e capacidade de organização do agricultor (formação de preços) e logística de entrega.

Do ponto de vista sanitário, alguns agricultores familiares precisaram regularizar suas agroindústrias e obter os alvarás sanitários que os possibilitassem participar das Chamadas Públicas. Salienta-se que muitos desses agricultores familiares, mesmo vinculados a cooperativas, possuem limitados conhecimentos acerca da comercialização, e a exigência de alvarás se constitui em uma das dificuldades enfrentadas pela CNE. Muitos agricultores e pequenas cooperativas participavam das Chamadas Públicas, mas sendo os alvarás uma exigência, muitas vezes acabavam desclassificadas.

Para Triches e Baccarin (2016), a legislação sanitária é percebida como uma dificuldade enfrentada também pelos agricultores familiares no Brasil, mais especificamente no que se refere a produtos pecuários. Conforme os autores, no caso de leite e carne, por exemplo, o processamento deve ocorrer em laticínios e frigoríficos, os quais, em geral, possuem plantas de grande porte. Belik (2016) destaca que a exigência de alvará sanitário se constitui em uma garantia para as prefeituras de que os fornecedores são empresas confiáveis e de que os produtos adquiridos são de qualidade. Porém, este autor explica que estas exigências também podem ser uma barreira para os agricultores familiares devido ao custo financeiro.

A rotulagem também é outra dificuldade destacada pela CNE. Alguns produtos, tais como pães, bolachas, cucas, em especial das agroindústrias, eram entregues em embalagens sem padronização, com datas de validade escritas a caneta. Assim, os 
Participação da agricultura familiar na alimentação escolar no município de Passo Fundo-RS ${ }^{1}$

extensionistas da Emater municipal realizaram oficinas sobre rotulagem de alimentos da agricultura familiar com o intuito de qualificar os produtos destes agricultores para que eles possuam um padrão de apresentação.

A logística também é uma das dificuldades apontadas pela CNE, pois os produtos perecíveis, tais como frutas, verduras e legumes, são entregues pelos fornecedores em cada uma das 70 escolas, já os produtos não perecíveis como arroz, feijão, leite em pó, massa, sucos e as carnes são entregues no depósito da CNE.

A entrega em um número expressivo de escolas é considerada pela CNE como uma barreira para a participação de agricultores familiares. Nesse sentido, Belik (2016) reforça que muitos agricultores produzem e comercializam produtos frescos, mas a entrega em cada escola, conforme é exigido nas Chamadas Públicas, torna-se inviável financeiramente para esses fornecedores.

As dificuldades destacadas vêm sendo superadas a partir da atuação da Emater municipal, auxiliando diretamente com os agricultores familiares e da UCP da Emater de Erechim, intervindo com as cooperativas, além de todo o empenho da CNE. O relacionamento entre os diferentes órgãos vem oportunizando o alcance de melhores resultados, fato que é reforçado por um extensionista da Emater ao expressar que "o mais interessante em todo o processo é que tudo é conversado" (E2).

\section{Considerações finais}

Nas escolas municipais de Passo Fundo a gestão do PNAE é centralizada na Prefeitura Municipal e as compras são realizadas pela CNE, tendo uma nutricionista como coordenadora Responsável Técnica. Assim, o objetivo deste trabalho foi analisar a participação da agricultura familiar nas compras da alimentação escolar nas escolas municipais de Passo Fundo, identificando as oportunidades e os desafios enfrentados pelos atores sociais que fazem a operacionalização do programa.

O município de Passo Fundo possui uma demanda importante em termos de alimentação escolar, visto que possui 70 escolas municipais e ainda atende oito escolas filantrópicas. A partir da análise realizada constatou-se que o aperfeiçoamento do processo de gestão do PNAE vem possibilitando elevar as compras de produtos da agricultura familiar na alimentação escolar, constituindo-se em uma oportunidade de comercialização dos produtos desta categoria social.

Dentre os principais desafios enfrentados no âmbito da operacionalização do PNAE neste município, destaca-se inicialmente o despreparo dos agricultores locais para participarem do mercado institucional, questões sanitárias, logística e rotulagem de produtos. Tais dificuldades vêm sendo enfrentadas com o auxílio dos atores sociais locais, evidenciando principalmente o esforço empreendido pela Emater, em conjunto com a CNE, buscando qualificar os agricultores familiares e suas cooperativas para atender a demanda da alimentação escolar local.

O PNAE passa por um processo no qual ocorrem avanços e recuos, constituindose em um projeto social e econômico que tem entre seus objetivos a mudança de 
hábitos de consumo alimentar, principalmente pela inclusão de produtos da agricultura familiar. A realidade, no entanto, ainda permanece bastante distante da Lei em Passo Fundo e é a partir da interação entre os diferentes atores sociais envolvidos com o Programa, tal como ocorre na gestão centralizada neste município, que o projeto do PNAE se materializa.

\section{Referências}

ABRAMOVAY, R. Entre Deus e o diabo: mercado e interação humana nas ciências sociais. Tempo social, v. 16, n. 2, p. 35-64, nov. 2004.

ALBERTI, V. Fontes orais: História dentro da História. In: PINSKY, C. B. (Org.). Fontes históricas. São Paulo: Contexto, 2008, p. 155-202.

ALBRECHT, A. L.; et al. A dinâmica de ATERS na efetivação do PNAE no município de Passo Fundo/RS. Disponível em: http://www.mda.gov.br/sitemda/sites/sitemda/files/user_img_1035/Oficial\%20Emate r\%20RS\%20\%28mercados\%20institucionais\%29_0.pdf. Acesso em: 05 jun. 2017.

AMARAL, V. R. do. Potencialidades e limites da política de alimentação escolar na promoção da agricultura familiar. 2016. 102f. Dissertação (Mestrado em Desenvolvimento) Universidade Regional do Noroeste do Estado do Rio Grande do Sul, ljuí.

ATLAS SOCIOECONÔMICO RS. Atlas Socioeconômico do Rio Grande do Sul. Conselhos Regionais de Desenvolvimento - COREDEs. Disponível em: http://www.atlassocioeconomico.rs.gov.br/conselhos-regionais-de-desenvolvimentocoredes. Acesso em: 02 jun. 2017.

BALEM, T. A. O Programa de Alimentação Escolar Brasileiro e a narrativa alternativa dos alimentos: convergências e desafios. 2015. 263f. Tese (Doutorado em Extensão Rural) Universidade Federal de Santa Maria, Santa Maria.

BELIK, W. Os limites para a expansão dos mercados locais. In: MARQUES, Flávia Charão; CONTERATO, Marcelo Antônio.; SCHNEIDER, Sérgio (Orgs.). Construção de mercados e agricultura familiar. Desafios para o desenvolvimento rural. Porto Alegre: UFRGS, 2016. p. $183-205$.

BRUM, A. J. Modernização da agricultura no Planalto Gaúcho. ljuí: Ed. Fidene, 1983. $204 \mathrm{p}$.

DELGADO, L. A. N.; FERREIRA, M. M. História do tempo presente e ensino de História. Revista História Hoje, v. 2, n. 4, p. 19-34, 2013.

FAO; OPAS. Organización de las Naciones Unidas para La Alimentación y La Agricultura; Organización Panamericana de La Salud. América Latina y el Caribe. Panorama de la seguridad alimentaria y nutricional. Sistemas alimentarios sostenibles para poner fin al hambre y la malnutrición. Santiago, 2017.

FEE. Fundação de Economia e Estatística. Perfil Socioeconomico. Corede Produção. Municípios do Corede em 2015. Disponível em: https://www.fee.rs.gov.br/perfilsocioeconomico/coredes/detalhe/?corede=Produ\%E7\%E3o. Acesso em: 20 mai. 2017. 
Participação da agricultura familiar na alimentação escolar no município de Passo Fundo-RS ${ }^{1}$

FERREIRA, M. M. História oral: velhas questões, novos desafios. In: CARDOSO, Ciro Flamarion; VAINFAS, Ronaldo (Orgs.). Novos domínios da história. Rio de Janeiro: Elsevier, 2012. p. 169-186.

FNDE. Fundo Nacional de Desenvolvimento da Educação. Cartilha Nacional da Alimentação Escolar. Brasília: 2015.

FNDE. Fundo Nacional de Desenvolvimento da Educação. Programa Nacional de Alimentação Escolar. Histórico. Disponível em: http://www.fnde.gov.br/programas/pnae/pnae-sobre-o-programa/pnae-historico.

Acesso em: 17 nov. 2016 .

FNDE. Fundo Nacional de Desenvolvimento da Educação. Aquisição de produtos da agricultura familiar para a alimentação escolar. 2a edição - versão atualizada com a Resolução CD/FNDE no 04/2015. Disponível em: http://www.fnde.gov.br/centrais-deconteudos/publicacoes/category/116-alimentacao-escolar?download=9815:pnaemanual-aquisicao-de-produtos-da-agricultura-familiar-para-a-alimentacao-escolar-2edicao. Acesso em: 01 dez. 2016b.

FNDE. Fundo Nacional de Desenvolvimento da Educação. Alunado por ação do Programa Nacional de Alimentação Escolar. Disponível em: http://www.fnde.gov.br/pnaeweb/publico/relatorioDelegacaoEstadual.do. Acesso em: 20 dez. 2017.

FRITZ FILHO, L. F. Análise das trajetórias das unidades de produção agrícolas do município de Passo Fundo/RS. 2009. 319f. Tese (Doutorado em Desenvolvimento Rural) Universidade Federal do Rio Grande do Sul, Porto Alegre.

GIL, A. C. Métodos e técnicas de pesquisa social. São Paulo: Atlas, 2016.

GRISA, C; SCHNEIDER, S. Três gerações de políticas públicas para a agricultura familiar e formas de interação entre sociedade e Estado no Brasil. In: GRISA, Cátia; SCHNEIDER, Sergio (Orgs.). Políticas públicas de desenvolvimento rural no Brasil. Porto Alegre: UFRGS, 2015. p. 161-200.

IBGE. Instituto Brasileiro de Geografia e Estatística. Passo Fundo. Rio Grande do Sul - RS. Histórico. IBGE, $s / d$. Disponível em: https://biblioteca.ibge.gov.br/visualizacao/dtbs/riograndedosul/passofundo.pdf.

Acesso em: 02 jan. 2017.

IBGE. Instituto Brasileiro de Geografia e Estatística. Bases e referenciais. Bases cartográficas. Mapas municipais. Disponível em: $\mathrm{ftp}$ //geoftp.ibge.gov.br/cartas_e_mapas/mapas_para_fins_de_levantamentos_estatis ticos/censo_demografico_2010/mapas_municipais_estatisticos/rs/passo_fundo_v2.pd f. Acesso em: 10 out. 2017 a.

IBGE. Instituto Brasileiro de Geografia e Estatística. Sinopse do Censo Demográfico 2010. Rio Grande do Sul. Disponível em: https://censo2010.ibge.gov.br/sinopse/index.php?dados=29\&uf=43. Acesso em: 13 mar. 2019b.

IBGE. Instituto Brasileiro de Geografia e Estatística. Censo Agropecuário 2017. Disponível

em: https://sidra.ibge.gov.br/tabela/6710\#/n6/4314100/v/183,184/p/all/c221/111195/c1 
Participação da agricultura familiar na alimentação escolar no município de Passo Fundo-RS ${ }^{1}$

2559/41148/c346/41149/c220/all/d/v184\%200/l/,p+c221+c12559+v,c346+t+c220/res ultado. Acesso em: 19 fev. 2019.

IBGE. Instituto Brasileiro de Geografia e Estatística. IBGE Cidades: Passo Fundo. Disponível em: https://www.ibge.gov.br/cidades-e-estados/rs/passo-fundo.html?. Acesso em: 12 mar. 2019.

LAMARCHE, H. Agricultura familiar: comparação internacional. Tradução de Ângela Maria Naoko Tijiwa. Campinas: Unicamp, 1993, v. 1-2.

MALUF, R. S. J. Mercados agroalimentares e a agricultura familiar no Brasil: agregação de valor, cadeias integradas e circuitos regionais. Ensaios FEE, v. 25, n. 1, p. 299-322, abr. 2004.

MDA. Ministério do Desenvolvimento Agrário. Alimentação escolar. Como funciona a compra e venda de produtos da agricultura familiar? Disponível em: http://www.mda.gov.br/sitemda/secretaria/saf-ali/como-funciona-compra-e-vendade-produtos-da-agricultura-familiar. Acesso em: 09 dez. 2017.

SCHNEIDER, S. Teoria social, agricultura familiar e pluriatividade. Revista Brasileira de Ciências Sociais, v. 18, n. 51, p. 99-121, fev. 2003.

SCHNEIDER, S. Mercados e agricultura familiar. In: MARQUES, F. C.; CONTERATO, M. A.; SCHNEIDER, S. Construção de mercados e agricultura familiar: desafios para 0 desenvolvimento rural. Porto Alegre: UFRGS, 2016. p. 93-140.

SCHNEIDER, S. Agricultura familiar y mercados. Boletín de Agricultura Familiar para América Latina y el Caribe, n. 17, en.-mar. 2017, p. 5-7.

SCHNEIDER, S.; CASSOL, A. Diversidade e heterogeneidade da agricultura familiar no Brasil e implicações para políticas públicas. In: DELGADO, G. C.; BERGAMASCO, S. M. P. P. (Orgs). Agricultura familiar brasileira: desafios e perspectivas de futuro. Brasília: Ministério do Desenvolvimento Agrário, 2017.

SEAD. Secretaria Especial de Agricultura Familiar e do Desenvolvimento Agrário. Perguntas frequentes. Disponível em: http://www.mda.gov.br/sitemda/dap/faq Acesso em: 18 mai. 2018.

TCU. Tribunal de Contas da União. Cartilha para conselheiros do Programa Nacional de Alimentação Escolar (PNAE). Brasília: TCU, 2017.

TEDESCO, J. C. Agrodiversidade, agroecologia e agricultura familiar. Velhas e novas faces de um processo de desenvolvimento na região de Passo Fundo - Pós-anos 90. Passo Fundo: UPF, 2006. p. 101-142.

TRICHES, R. M. Repensando o mercado da alimentação escolar: novas institucionalidades para o meio rural. In: GRISA, C.; SCHNEIDER, S. (Orgs.). Políticas públicas de desenvolvimento rural no Brasil. Porto Alegre: UFRGS, 2015. p. 161-200.

TRICHES, R. M.; BACCARIN, J. G. Interações entre alimentação escolar e agricultura familiar para o desenvolvimento local. In: TEO, C. R. P. A.; TRICHES, R. M. (Orgs.). Alimentação escolar: construindo interfaces entre saúde, educação e desenvolvimento. Chapecó: Unochapecó, 2016, p. 89-109.

WANDERLEY, M. N. B. Raízes históricas do campesinato brasileiro. In: ENCONTRO ANUAL DA ANPOCS, 20, 1996, Caxambu. Disponível em: http://www.reformaagrariaemdados.org.br/sites/default/files/Ra\%C3\%ADzes\%2OHist 
Participação da agricultura familiar na alimentação escolar no município de Passo Fundo-RS ${ }^{1}$

oricas\%20do\%20Campesinato\%20Brasileiro\%20-

\%20Maria\%20de\%20Nazareth\%20Baudel\%20Wanderley\%20-\%201996.pdf. Acesso em: 04 abr. 2018.

WANDERLEY, M. N. B. Raízes históricas do campesinato brasileiro. In: TEDESCO, J. C. (Org.). Agricultura familiar: realidades e perspectivas. Passo Fundo: EDIUPF, 1999, p. $23-$ 56.

\section{Sobre a autora:}

Indaia Dias Lopes, Doutoranda em História (PPGH/UPF); Bolsista Prosuc/Capes; Mestra em Desenvolvimento Regional (PPGDR/Unijuí); Economista (UFSM). Email: indaia_lopes@yahoo.com.br 